\title{
Supratentorial Ependymal Tumor
}

National Cancer Institute

\section{Source}

National Cancer Institute. Supratentorial Ependymal Tumor. NCI Thesaurus. Code

C131611.

An ependymal tumor arising from the supratentorial region of the brain. 